\title{
'n Lede-opname belig die hede en toekoms van die Akademie
}

\author{
C.F. Smit en M.J. van der Linde \\ Departement Statistiek, Universiteit van Pretoria, Pretoria, 0002 \\ J.B.Z. Louw \\ S.A. Akademie vir Wetenskap en Kuns, Privaat sak X11, Arcadia, 0007
}

Ontvang Augustus 2000; aanvaar September 2000

\section{UITTREKSEL}

Ingevolge 'n besluit deur die Raad van die Akademie is 'n lede-opname per vraelys onder gewone lede van die Akademie vroeg in 2000 onderneem. Die vraelys is opgestel om lede se oordeel oor verskeie aspekte rakende die Akademie vas te stel. Uit die respons van 46 persent van die lede is belangrike inligting oor die gesindheid van lede oor spesifieke sake verkry. Dit het die Raad van die Akademie in staat gestel om besluite te neem oor die voortbestaan en die oogmerke van die Akademie en om 'n lys op te stel van sake waaraan prioriteitsaandag gegee moet word.

\begin{abstract}
A member survey sheds light on die present and the future of the Akademie

Following a decision by the Board of the Akademie a questionnaire was compiled to conduct a member survey amongst ordinary members of the Akademie during the first months of 2000. The questionnaire was structured to determine the opinions of members on various aspects concerning the Akademie. The responses received from 46 per cent of members provided important information about the attitudes of members regarding specific issues. This enabled the Board to take decisions about the continued existence and objectives of the Akademie and to compile a list of matters that should be given priority.
\end{abstract}

\section{INLEIDING EN AGTERGROND}

Die Raad van die Suid-Afrikaanse Akademie vir Wetenskap en Kuns (die Akademie) het gedurende 1999 besluit dat 'n omvattende wetenskaplike opname per vraelys onder akademielede gedoen moet word oor sake soos die doelstellings van die Akademie, sy struktuur, lidmaatskap, ledegeld, publikasies, bekronings, jaarvergadering, ens. Dié besluit het gevolg op 'n tydperk van ingrypende administratiewe en finansiële herskikking van die Akademie gedurende 1998 en 1999. Die herskikkingsproses het gepaardgegaan met ernstige besinning oor die bestaan en die toekoms van die Akademie in die lig van die veranderde politieke bedeling in Suid-Afrika en die wyse waarop dit die tradisionele voedingsbodem en steunbasis van die Akademie, asook sy doelstellings en status en die posisie van die Afrikaanse taal, geaffekteer het.

Verwant hieraan was die houding van die regering teenoor wetenskapsakademies, wat verstaan is as sou daar ruimte wees vir slegs een staatsondersteunde wetenskapsakademie in SuidAfrika, wat boonop sy sake deur medium van Engels sou bedryf. Die Akademieraad wou dus by sy lede vasstel en wou vir homself duidelikheid verkry oor die vraag of hy 'n bestaansreg het en indien wel, in watter vorm en met watter doelstellings hy moes voortbestaan. Die reaksie van akademielede op pertinente vrae in hierdie verband sou ' $n$ belangrike inset wees in die besinningsproses.

Die feite oor die Akademie is kortliks die volgende: Die Akademie is in 1909 kort voor Uniewording gestig. Dit was midde in die debat oor die amptelike tale van die nuwe staat. Die Afrikaanse gemeenskap was verdeeld oor die vraag of die
Afrikaanse taal, onontwikkel en onverfynd soos dit indertyd was, of Hooghollands, in die nuwe bedeling die taal van die HollandsAfrikaanssprekende deel van die bevolking sou wees. Hierdie vraagstuk is enkele jare later in akademiegeledere besleg toe die Akademie homself met die Afrikaanse taal vereenselwig het.

Die doel met die stigting van die Akademie was om om te sien na Nederlandse (insluitend die Afrikaanse) taal, letterkunde, kuns, geskiedenis en oudheidkunde in Suid-Afrika en om leiding in hierdie sfere te gee. Die Akademie het oor die 91 jaar van sy bestaan ' $n$ besonder belangrike rol gespeel in die standaardisering van die Afrikaanse taal, in die ontwikkeling van die Afrikaanse letterkunde, kuns en wetenskapsbeoefening, in die uitbou van Afrikaans tot 'n wetenskapstaal en 'n taal vir gebruik in alle omgewings en op alle vlakke. Derhalwe het hy vir die grootste deel van die twintigste eeu 'n belangrike bydrae gemaak tot die bemagtiging van alle sprekers van Afrikaans.

\section{OORSIG OOR DIE PROSES}

\section{Vraelysontwikkeling}

By die aanvang van die ondersoek is 'n konsepvraelys deur lede van die Akademieraad en die fakulteitsrade opgestel wat daarna deur personeel van Statomet van die Universiteit van Pretoria aangepas is met die oog op rekenaar- en statistiese verwerking. Die vraelys is tot 'n dokument in standaardformaat van agt bladsye gefinaliseer en vermenigvuldig. Die vrae is in ses afdelings ingedeel.

Die opname self

Die vraelys is per pos aan elk van sowat 920 gewone lede van die Akademie besorg, tesame met 'n antwoordbetaalde koevert. 
Rustende lede is nie gevra om die vraclys in te vul nic. Elke vraclys het die nommer van die betrokke lid bevat met dic oog op opvolgversoeke indien die respons nie tydig ontvang sou word nie. In die dekbrief by die vraclys is respondente verseker dat inligting vertroulik hantecr sou word. Uiteindelik is 422 bruikbarc vraclyste terugontvang, wat 'n responskocrs van 46 persent verteenwoordig.

\section{Statistiese verwerking}

Die response op die ingevulde vraclyste is per hand gekodeer en rekenaarmatig vasgelê en gekontroleer. Hierna is eersteordeanalises gedoen om enige oorblywende foute uit te skakel. $\mathrm{A}$ die inligting is as rekenaarlêers gestoor en volgens standaard statistiese tegnieke ontleed. ' $n$ Volledige verslag is hicruit opgestel, waarvan dic essensie in dic volgende afdeling bespreck word.

\section{Verslagdoening aan die Akademie- en fakulteitsrade en jaarvergadering}

Die verslag is op 3 Junic 2000 tydens 'n daglange byeenkoms van dic lede van dic twee fakulteitsrade en dic Akademicraad (altesaam 24 persone) voorgelê en onder leiding van 'n fasilitecrder bespreck Dic navorser van Statomet het dic bevindinge in die verslag aan die hand van grafieke en ander voorstellings toegelig, waarna die bevindinge sistematics bespreek is. Uit die daglange gesprek het ' $n$ aantal bevindinge voortgevloci wat op skrif gestel is en wat drie weke later by formele vergaderings van die fakulteitsrade en dic $\Lambda$ kademicraad voorgelê is. Die Voorsitter van dic Akademic het op grond van die bevindinge van dic ondersock en dic gesprek daaroor bepaalde voorstelle geformulecr oor 'n tockomssiening van dic Akademic. Die verskillende liggame het hulle steun aan dic voorstelle toegesê sodat dic Voorsitter in sy verslagdocning aan dic jaarvergadering van dic $A$ kademic op 22 Junic 2000 namens die $\Lambda$ kademicraad bepaalde standpunte kon stel.

\section{BEVINDINGE VAN DIE OPNAME}

\section{Biografiese inligting van respondente}

In totaal is 422 bruikbare vraclyste terugontvang. Die gemiddelde ouderdom van respondente was 57.7 jaar en dic standaardafwyking 10.8 jaar. Hierdie twee syfers vergelyk goed met die ooreenstemmende syfers vir die totaal van $969 \mathrm{ledc}$, te wete 58.8 en 10.5 onderskeidelik. Voorts was 45 persent van dic respondente lede van dic Fakulteit Kuns en Geesteswetenskappe en 55 persent was lede van die Fakulteit Natuurwetenskap en Tegnick. Dit vergelyk goed met dic verspreiding van al die lede van dic Akademie oor die twec fakulteite: 44 persent en 56 persent onderskeidelik. Negentig persent van die respondente was manlik en 10 persent was vroulik. Wat beroepstatus betref, het 50 persent van die respondente aangedui dat hulle praktiserende akademici is, 15 persent dat hulle berocpspraktisyns is, 14 persent dat hulle verbonde is aan dic openbare sektor, 19 persent dat hulle aktief is in dic privaat scktor, twee persent is uitvoerende of skeppende kunstenaars en 32 persent is pensioenarisse (dit was moontlik om meer as cen beroepskategorie aan te dui - vandaar ' $n$ totale persentasic van meer as 100 persent). Dic mecrderheid respondente is in dic groot sentra met akademiese inrigtings woonagtig: 33 persent in Pretoria, 21 persent in die Wes-Kaap, 16 persent in dic Vrystaat, 12 persent in Johannesburg/Krugersdorp/Germiston, 11 persent in Potchefstroom en die res in sentra soos Port-Elizabeth, KwaZulu-Natal, Pietersburg en George. Sewe-cn-tagtig persent van die respondente behoort aan nasionale vakverenigings en 53 persent behoort ook aan internasionale vakverenigings. Wat wetenskaplike publikasies oor die afgelope vier jaar betref, toon die opname dat 52 persent van die respondente in nasionale vaktydskrifte gepubliseer het teenoor 46 persent in internasionale tydskrifte. Een-en-sestig persent van die respondente het in dieselfde tydperk buitelandse kongresse bygewoon - hoofsaaklik lede in die ouderdomsgroepe onder 60 jaar.

\section{Algemene opmerking insake rapportering van response}

Dic meeste van dic vrac rondom lede se opinic of waardcring van sake is op 'n 10-puntskaal beantwoord. 'n Respons van 0 dui aan dat daar glad nic met die gegewe stelling saamgestem word nic, 10 dui volkome instemming aan en 5 matige instemming. ' $n$ Punt bo 5 word dikwels as 'n positiewe mate van instemming beskou en 'n punt onder 5 as negatief. 'n Volledige persentasieverdeling van response per vraag oor die kategorieë van opsies $(0,1,2, \ldots, 10)$ word nic hicrin gerapportecr nic. Ter wille van 'n meer beknopte bchandeling van terugvocring is die gemiddelde punt van respondente asook dic standaardafwyking en variasickoëffisiënt in tabel 1 gelys vir al dic betrokke vrae. Let op dat dic variasickoëffisiënt 'n uitdrukking is van dic standaardafwyking as persentasie van die gemiddeld. By die bespreking van die gegewens in die tabel word hoofsaaklik gekyk na die gemiddeld (as opsomming van alle respondente se antwoorde) en dic variasiekoëffisiënt (as maatstaf van eenstemmigheid onder respondente). In sekere gevalle, byvoorbecld waar respondente nic baic eenstemmig is nic, word ook 'n aanduiding gegec van opvallend hoc̈ persentasies response aan eindpunte van die skaal. Sodanige persentasies word nie in tabel 1 weergegee nic. Verder word in sommige gevalle ook getoets of biografiese verskille, soos ouderdom, fakulteit en berocpstatus enige verskil in respons tot gevolg kon gehad het.

\section{Missie en doelstellings van die Akademie}

Respondente gec gemiddeld 'n baic hoë waardering vir dic noodsaaklikheid van dic Akademie, te wete 'n punt van 8.1 op die 10-puntskaal. Verder is hulle ook baie censtemmig hieroor, soos blyk uit die variasiekoëffisiënt wat kleiner is as 25 persent. Respondente is ook in 'n hoë mate van mening (gemiddelde punt bo 8) dat die $\Lambda$ kademic se missic stecds geldig is en dat dic belangrikste taak van dic Akademic is om dic gebruik en gehalte van $A$ frikaans in dic wetenskap en die kunste te bevorder. Respondente is egter in ' $n$ veel kleiner mate van mening dat die $\Lambda$ kademic sy doelstellings, soos in dic $\Lambda$ kademiewet verwoord, effektief bereik (gemiddeld slegs 5.9 met 'n variasickoëffisiënt van 29.9 persent). Die hoë gemiddelde punt (8.3) by die vraag of $\Lambda$ frikaans nog die $\Lambda$ kademie nodig het, tesame met die klein variasickoëffisiënt van 26 persent stuur waarskynlik 'n belangrike sein vir dic Akademieraad.

Respondente is ook positicf oor hulle behoeftes aan kontak met Afrikaanssprekende wetenskaplikes (vraag 24 met gemiddeld 7.7) asook gesprek en kontak oor vak-en wetenskapsgrense (vraag 26 met gemiddeld 6.8). Dic gemiddelde punt van 5.5 vir die vraag of respondente deelneem an die aktiwiteite van die $A$ kademie gee 'n telcurstellende beeld van lede se belangstelling in die aktiwiteite.

\section{Lidmaatskap en ledegeld}

Op dic vraag of dit vir die respondent belangrik is om sy/haar lidmaatskap van dic $A$ kademic in stand te hou, het 84 persent bevestigend geantwoord. 'n Vergelyking van respondente in die twee fakulteite toon geen statisties betckenisvolle verskille ten opsigte van hicrdic vergelyking nic. Net so is daar nic betekenisvolle responsverskille by verskillende ouderdomsgroepe nie. 
Tabel 1 Opsomming van response op vrae op 'n 10-puntskaal

\begin{tabular}{|c|c|c|c|c|}
\hline Vraag & Getal & Gemiddeld & $\begin{array}{c}\text { St. } \\
\text { afwyking }\end{array}$ & $\begin{array}{l}\text { Var. } \\
\text { koëf. }\end{array}$ \\
\hline V15* Is dic $\wedge$ kademic steeds nodig? & 420 & 8.1 & 2.0 & 24.1 \\
\hline V14 Is sy missie steeds geldig? & 419 & 8.1 & 2.2 & 27.0 \\
\hline V17 Belangrikste taak: Bevordering van wet. en kuns? & 420 & 6.8 & 2.7 & 39.6 \\
\hline V18 Belangrikste taak: Bevordering v. $\Lambda$ fr. in die wet. en kuns? & 419 & 8.2 & 2.2 & 26.5 \\
\hline V19 Bereik dic $\wedge$ kademie sy doclstellings effekticf? & 419 & 5.9 & 1.8 & 29.9 \\
\hline V23 Het Afrikaans dic Akademic nog nodig? & 419 & 8.3 & 2.2 & 26.0 \\
\hline V24 Is kontak met $\Lambda$ fr.sprekende wetenskaplikes belangrik? & 419 & 7.7 & 2.2 & 28.0 \\
\hline V25 Neem u decl aan aktiwiteite van dic $\wedge$ kademic? & 417 & 5.5 & 2.6 & 47.5 \\
\hline \multirow{2}{*}{\multicolumn{5}{|c|}{$\begin{array}{l}\text { V26 Behoefte aan gesprek oor vak- en wetenskapsgrense? } \\
\text { Motivering vir behoud van akademielidmaatskap: }\end{array}$}} \\
\hline & & & & \\
\hline V33 Status gekoppel aan lidmaatskap? & 418 & 4.8 & 3.0 & 61.1 \\
\hline V34 Lofwaardige doelstellings van dic Akademic? & 418 & 7.8 & 1.9 & 24.0 \\
\hline V35 Bevordering van wet. en kuns binne kultuurverband? & 419 & 6.8 & 2.5 & 36.2 \\
\hline V36 Bevordering van $\Lambda$ frikaans as decl van missic? & 419 & 8.3 & 2.1 & 25.9 \\
\hline V37 Akademie is 'n multidissiplinêre organisasic? & 419 & 7.3 & 2.2 & 30.3 \\
\hline V44 Gehaltepunt toegeken aan akademictydskrifte & 406 & 7.2 & 1.7 & 23.7 \\
\hline V45 Is 'n $\Lambda$ frikaanse publikasicplatform vir u belangrik? & 417 & 6.6 & 2.9 & 44.2 \\
\hline V46 Neem u kennis van inhoud van 'n akademietydskrif? & 416 & 7.1 & 1.9 & 27.2 \\
\hline \multirow{2}{*}{\multicolumn{5}{|c|}{$\frac{\text { V47 }}{\text { Moct publikasiegeleenthe }}$}} \\
\hline & & & & \\
\hline V48 Geniet hoë aansien onder akademiclede? & 414 & 8.1 & 1.6 & 19.7 \\
\hline V49 Genict hoë aansien onder nie-lede? & 413 & 6.2 & 2.3 & 36.3 \\
\hline V50 Is partikulier $A$ frikaanse tockennings? & 412 & 7.2 & 2.0 & 27.8 \\
\hline V51 Aansien hoofsaaklik binne Afrikaanse gemeenskap? & 414 & 7.0 & 2.1 & 29.7 \\
\hline V52 Moct alle S.A. wetenskaplikes oorweeg word? & 412 & 6.9 & 3.1 & 45.3 \\
\hline V53 Keuringsproses is nic deursigtig genocg nie? & 404 & 5.2 & 2.6 & 50.3 \\
\hline V54 Moet persone deur kollegas genominecr word? & 411 & 7.1 & 2.2 & 31.1 \\
\hline V55 Moet persone ook cic werk kan voorlê? & 412 & 6.3 & 2.8 & 45.2 \\
\hline V56 Is daar te vecl tockennings? & 410 & 4.2 & 2.9 & 69.2 \\
\hline \multirow{2}{*}{\multicolumn{5}{|c|}{$\begin{array}{l}\text { V57 Doen te vecl tockennings afbreuk aan prestige do } \\
\text { Jaarvergadering: }\end{array}$}} \\
\hline & & & & \\
\hline V60 Verkies om werk in Afrikaans voor te dra? & 416 & 7.6 & 2.4 & 32.2 \\
\hline V61 Ook aantreklik om werk in ander taal voor te dra? & 412 & 4.3 & 3.0 & 68.8 \\
\hline V62 "Vakkongresmodel" met alle S.A. wetenskaplikes nodig? & 414 & 6.5 & 3.0 & 46.8 \\
\hline V63 Oorweeg u bywoning in onmiddellike omgewing? & 417 & 7.7 & 2.2 & 28.7 \\
\hline V64 Oorweeg u bywoning minstens $200 \mathrm{~km}$ ver? & 418 & 4.2 & 2.8 & 66.5 \\
\hline V65 Jaarvergadering is belangrik, al word nic bygewoon? & 420 & 6.8 & 2.6 & 37.9 \\
\hline V66 Verwag multidissiplinêre gesprek oor Internet? & 416 & 6.9 & 2.5 & 36.8 \\
\hline
\end{tabular}

- Nota: Nommers vooraan (V15, V16, ens.) dui die nommer van die vraag in die vraelys aan. 
Vrae 33 tot 37 hantecr verskillende redes wat lede motiveer om lid van dic Akademic te bly. Die belangrikste en tweede belangrikste redes is onderskeidelik die feit dat die $A$ kademic $\Lambda$ frikaans bevorder en dat hy lofwaardige doelstellings nastreef. Die rede wat lede die minste motiveer, is die status verbonde aan lidmaatskap (gemiddeld 4.8). Ilier val die hoë variasickoëffisiënt van 61 persent op, wat 'n weerspiëling is van die feit dat 43 persent respondente ten minste 'n positiewe punt van 6 op die 10-puntskaal gegec het. Dit is waarskynlik 'n aanduiding dat lede dic $\Lambda$ kademic steeds hoog ag.

$\Lambda$ gt-en-sestig persent van die respondente beskou die ledegeld as baic billik tot billik en die meerderheid aanvaar dat verhoging in ledegeld in die orde van die inflasickoers behoort te wees.

\section{Die akademietydskrifte en publikasieforums}

Respondente gee gemiddeld 'n gehaltepunt van 7.2 aan dic akademietydskrif wat hulle ontvang. Hicr is verder 'n vergelyking getref tussen response vir die twee fakulteite en gevind dat lede van die Fakulteit Kuns en Geesteswetenskappe gemiddeld 'n betekenisvol hoër punt tocken as lede van dic Fakulteit Natuurwetenskap en Tegnick. Dit is opvallend dat slegs 26 persent respondente oorwegend in Afrikaans publiseer en soveel as 56 persent oorwegend in Engels. Die belangrikheid van 'n Afrikaanse publikasieplatform kry 'n gemiddelde punt van 6.6 (bykans 20 persent van die respondente ken 'n punt van 10 op die skaal toe), terwyl daar grootliks afwysend gereageer word op dic vraag of dic $\Lambda$ kademic publikasiegeleentlede in Engels moct ondersock ('n gemiddeld van slegs 4.6). Hier is dic opvallend hoë variasickoëffisiënt van 72.1 persent ' $n$ aanduiding dat daar tog ' $\mathrm{n}$ groot persentasie positicwe respons was op so 'n moontlikheid (43 persent het ten minste 'n punt van 6 op dic skaal toegeken). Respondente ken gemiddeld 'n punt van 7.1 toc aan die mate waarin hulle kennis necm van dic inhoud van dic akademictydskrif wat hulle ontvang.

\section{Akademiepryse}

Vrae 48 tot 51 handel oor die aansien en beskouing onder verskillende groepe mense oor akademiepryse. Indien die respons op dic mening van lede oor dic aansien van bekronings binne en buite dic $\Lambda$ kademie vergelyk word, blyk dit dat, hoewel dic buite-aansien lacr as dic binne-aansien is (gemiddeld 6.2 tecnoor 8.1), dic bekronings volgens respondente se opinic tog oor die algemeen hoë aansien geniet. Dic bekronings word egter in ' $\mathrm{n}$ redelik hoë mate (gemiddeld 7.2) as partikulier $\Lambda$ frikaans beskou.

Vrac 52 tot 55 neem die keuringsproses onder beskouing. In geheel gesien kom dit voor of respondente taamlike instemming met die huidige proses het (dic lac punt van 5.2 reenoor dic negatiewe stelling dat dic keuringsproses nic deursigtig genocg is nic, reflekteer die feit dat 63 persent positicf vocl oor dic deursigtigheid van die proses). $\Lambda \mathrm{s}$ dic response op vrae $54 \mathrm{cn}$ 55 vergelyk word, kom dit voor dat hoewel die huidige stelsel van voorstelle deur kollegas en dic portuurgroep die beste geag word, dic moontlikhcid om cic werk voor te lê nic buite rekening gelaat kan word nie. Ten slotte, wat die hocveclheid tockennings en die effek daarvan betref, oordecl respondente dat dit nic 'n probleem is nic, hoewel daar tog ' $n$ aanduiding is van verskeic persone wat hieroor kommer kan hê.

\section{Jaarvergadering}

Op die vraag oor die model waarop dic jaarvergadering aangebied behoort te word ("volkskongres-" of "vakkongresmodel"), het 77 persent van die respondente die vakkongresmodel verkies wat moontlike verandering in dic huidige stand van sake suggereer. Referente wil ecrder hulle voordragte in $\Lambda$ frikaans gee (gemiddeld 7.6), hoewel 35 persent dit ook aantreklik vind om dit in 'n ander taal te gec. 'n Taamlike hoë punt van 6.5 dui aan dat heelwat lede positicf vocl oor dic betrek van alle SuidAfrikaanse wetenskaplikes by dic kongres. Vrac 63 tot 65 handel oor respondente se bywoning van die jaarvergadering. $\Lambda$ fstand en koste specl waarskynlik ' $n$ belangrike rol in hicrdic opsig, maar die feit dat 30 persent die geleentheid as onbelangrik beskou, verdien tog wel aandag.

\section{Die kuberruinte}

Drie-en-sewentig persent van die respondente beskou 'n multidissiplinêre gesprek oor die Internet in 'n positicwe lig (gemiddelde punt van 6.9).

\section{DIE PAD VORENTOE}

Die Raad van dic $\Lambda$ kademic het in die lig van die bevindinge uit die opname op 'n omvattende wyse na die toekomsmoontlikhede vir die $A$ kademie gekyk en het 'n aantal opsies vir dic herposisionering en voortbestaan van dic $\Lambda$ kademic oorweeg. Dit het geskied teen die agtergrond van die feit dat die getal gewone lede van die $\Lambda$ kademic oor die afgelope aantal jare afgeneem het, ten spyte daarvan dat nuwe lede aangesluit het, dat die finansiële posisie van dic $\Lambda$ kademic deur die likwidering van vaste bates en die vermindering van uitgawes verbeter het, maar weens jaarlikse lopende tekorte steeds in 'n gevaarsone verkecr en dat die staatsubsidic wat aan die $\Lambda$ kademic betaal is, gestaak is.

Nadat verskeic opsies oorweeg is, het dic $\Lambda$ kademieraad op 22 Junic 2000 verskcic aanbevelings wat op grond van dic resultate van die ondersock geformuleer is, oorweeg en verskeic besluite genecm. Die belangrikste hicrvan wat in die algemeen van belang is, is dic volgende:

- Dat die $\Lambda$ kademie onder sy huidige naam, dus as dic Suid$\Lambda$ frikaanse $\Lambda$ kademic vir Wetenskap en Kuns moct voortbestaan en dat die missic en doclstellings van dic $\Lambda$ kademic onveranderd moct bly.

- Dat dic Raad aandag moct gec aan bepaalde aanbevelings oor dic omvorming van dic Akademie, maar dat dic Akademic sy werksaamhede nie inkrimp nie.

- Dat dic organisasiestruktuur van die $\Lambda$ kademic heroorweeg word, maar dat dic huidige indeling van fakulteite bchou moet word en dat verseker moet word dat afdelings, werkgemeenskappe en konmissies onderling koördinecr ten einde die doelstelling van interdissiplinêre kontak en samewerking te bevorder.

- Dat die Iedetal van dic $\Lambda$ kademic uitgebrei word, veral in dic ouderdomsgroep 31 tot 49 jaar en in onderverteenwoordigde groepe.

- Dat dit vir nic- $\Lambda$ frikaanssprekers moontlik gemaak moet word on lid te word indien hulle die oogmerke van die $\Lambda$ kademic en die doelstellings van die betrokke fakulteit onderskryf.

- Dat die uitgee van albei tydskrifte voortgesit word, maar dat dic uitgee van elektroniese weergawes oorweeg word.

- Dat ondersock ingestel word na dic uitgee van Afrikaanse manuskripte wat nie kommersieel uitgegee kan word nie.

- Dat meer erkenning gegee moet word aan werk en bydraes wat deur medium van Engels gedoen word en dat bekronings en tockennings aan 'n breër spektrum van wetenskaplikes en kunstenaars gemaak moet word.

- Dat dic wyse waarop dic nasionale simposium aangebicd word, heroorweeg word. 